Article

\title{
Effect of Iminodiacetic Acid-Modified Nieuwland Catalyst on the Acetylene Dimerization Reaction
}

\author{
Yanhe You, Juan Luo, Jianwei Xie * and Bin Dai * \\ Key Laboratory for Green Processing of Chemical Engineering of Xinjiang Bingtuan, \\ School of Chemistry and Chemical Engineering, Shihezi University, North 4th road, \\ Shihezi 832003, China; shzu_yanheyou@sina.com (Y.Y.); shzu_juanluo@sina.com (J.L.) \\ * Correspondence: cesxjw@foxmail.com (J.X.); db_tea@shzu.edu.cn (B.D.); \\ Tel.: +86-993-2057213 (J.X. \& B.D.); Fax: +86-993-2057270 (J.X. \& B.D.)
}

Received: 19 November 2017; Accepted: 16 December 2017; Published: 19 December 2017

\begin{abstract}
The iminodiacetic acid-modified Nieuwland catalyst not only improves the conversion of acetylene but also increases the selectivity of monovinylacetylene (MVA). A catalyst system containing $4.5 \%$ iminodiacetic acid exhibited excellent performance, and the yield of MVA was maintained at $32 \%$ after $24 \mathrm{~h}$, producing an increase in the yield by $12 \%$ relative to the Nieuwland catalyst system. Based on a variety of characterization methods analysis of the crystal precipitated from the catalyst solution, it can be inferred that the outstanding performance and lifetime of the catalyst system was due to the presence of iminodiacetic acid, which increases the electron density of $\mathrm{Cu}^{+}$and adjusts the acidity of the catalytic solution.
\end{abstract}

Keywords: acetylene dimerization; selectivity; performance; monovinylacetylene; iminodiacetic acid-modified Nieuwland catalyst

\section{Introduction}

As one of the seven main synthetic rubber materials, chloroprene (CR) possesses good mechanical properties and chemical stability [1] and is widely used in the adhesive and automobile industries and also in other fields [2,3]. Acetylene dimerization facilitated by the Nieuwland catalyst to produce monovinylacetylene (MVA) is the key step in the acetylene-based process for CR synthesis [4]. The main process of this reaction is shown in the Scheme $1 . \mathrm{CuCl}, \mathrm{NH}_{4} \mathrm{Cl}$ (or $\mathrm{KCl}$ ) and water constitute the traditional Nieuwland catalyst, which has several advantages, such as being environmentally friendly, convenient to prepare, and low reaction temperature [5,6]. However, the drawbacks of this catalytic system include low acetylene conversion rates and low MVA selectivity. Thus, much effort is still needed to develop a more stable and efficient Nieuwland catalytic system to further improve the activity and selectivity of the acetylene dimerization reaction.

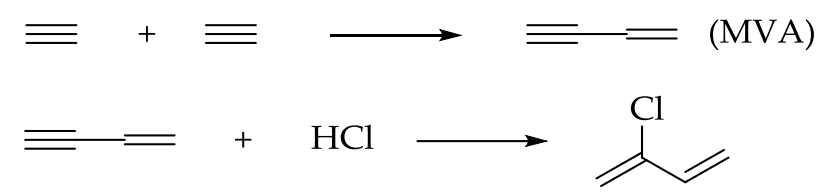

Scheme 1. Acetylene-based process for 2-chloro-1,3-butadiene production.

Because of the practical importance and the long history of the Nieuwland catalyst, recent studies on the reaction mechanism [1,6-9], catalyst structure $[10,11]$, and factors affecting the catalytic performance [11-19] have attracted significant attention. In general, it catalyzes a homogenous transition metal-catalyzed organic transformation; the addition of a second metal and ligand/additive 
results in changes in the electronic structure of the active metal, thus causing change in the performance of the catalyst; the change in the electronic structure of the active metal may be due to an electron transfer between the active metal and second metal or ligand/additive. In the catalytic recycling of acetylene dimerization, the electron transfer from $\mathrm{Cu}$ in $\mathrm{Cu}_{n} \mathrm{Cl}_{n+1}^{-}$(the active component in the Nieuwland catalyst) to the $\pi^{*}$ orbital of the $\mathrm{C} \equiv \mathrm{C}$ bond is an important step, which acts as an activating $\mathrm{C} \equiv \mathrm{C}$ bond. Additionally, when the electron density of $\mathrm{Cu}(\mathrm{I})$ is higher, a higher catalytic activity is obtained. Consequently, several groups have successfully improved the acetylene dimerization reaction using this strategy. For example, Tao et al. reported that the addition of urea [20], phosphine ligands [21], $\mathrm{LaCl}_{3}$ [22,23], and $\mathrm{CeCl}_{3}$ [24] to a Nieuwland catalyst solution can effectively enhance the acetylene conversion or MVA selectivity. Han et al. reported that the addition of DL-alanine to the Nieuwland catalyst can reduce the activity of acetylene dimerization and improve the MVA selectivity [25]. We also found that the addition of $\mathrm{SrCl}_{2}$ [26], $\mathrm{ZnCl}_{2}$ [27], PEGs [28], and $\mathrm{CuCl}_{2}$ [9] can improve the selectivity of MVA or the lifetime of the catalyst. However, these modified catalysts can only improve either the acetylene conversion or MVA selectivity, and simultaneous improvements in conversion and selectivity have not been reported in the literature.

In this paper, we report iminodiacetic acid as an efficient ligand, which can simultaneously improve acetylene conversion and MVA selectivity, for acetylene dimerization catalyzed using the Nieuwland catalyst. With the iminodiacetic acid-modified Nieuwland catalyst, a 38.0\% yield for acetylene conversion and $84.2 \%$ yield for MVA selectivity were obtained; the yields are comparatively higher than that obtained with the traditional Nieuwland catalyst. Moreover, the structures and reaction mechanism of the catalysts are also discussed. These results provided a new idea for improving the performance of Nieuwland catalyst, and this method is viable for use in both laboratory research and large industrial scales for acetylene-based CR production in the future.

\section{Results and Discussion}

\subsection{Catalytic Activities of NC and L-NC}

Initially, the catalytic performances of NC and L-NC were tested under fixed reaction conditions (space velocity of acetylene $=105 \mathrm{~h}^{-1}$, reaction temperature $=80^{\circ} \mathrm{C}, \mathrm{L}: \mathrm{CuCl}=0.03: 1$ ), and the results are shown in Figure 1 and Table 1. For acetylene conversion, all five ligands promoted the initial catalytic activity of NC and enhanced the catalyst stability for acetylene dimerization. The order of the catalyst activity is $\mathbf{L}_{4}-\mathrm{NC}>\mathbf{L}_{\mathbf{1}}-\mathrm{NC}>\mathbf{L}_{3}-\mathrm{NC}>\mathbf{L}_{2}-\mathrm{NC}>\mathbf{L}_{5}-\mathrm{NC} \approx \mathrm{NC}$. For MVA selectivity, all the L-NCs exhibited good selectivity in the range of $76-87 \%$, whereas there was only $76 \%$ MVA selectivity for NC. This was surprising given the previous findings that a higher acetylene conversion resulted in lower MVA selectivity. Taken together, $\mathbf{L}_{\mathbf{1}}$ is the most efficient ligand in this reaction with $29.3 \%$ acetylene conversion and $84.6 \%$ MVA selectivity. Subsequently, the results of the effect of the amount of $\mathbf{L}_{\mathbf{1}}$ showed that an optimal catalytic performance for acetylene dimerization was achieved when $4.5 \%$ of $\mathbf{L}_{\mathbf{1}}$ was used, which is shown in Figure 2 and Table 2. The acetylene conversion and MVA selectivity were $38 \%$ and $84.2 \%$, respectively, with a $12 \%$ increase in yield in comparison with the NC system.

Table 1. Effect of $\mathbf{L}_{\mathbf{1}}-\mathbf{L}_{5}$ (3\%) for acetylene dimerization.

\begin{tabular}{cccc}
\hline Catalysts & Acetylene Conversion (\%) & MVA Selectivity (\%) & Yield (\%) \\
\hline NC & 26.4 & 76.4 & 20.1 \\
L $_{1}$-NC & 29.3 & 84.6 & 24.8 \\
L $_{2}$-NC & 27.3 & 87.5 & 23.8 \\
L $_{3}$-NC & 28.8 & 79.4 & 22.9 \\
L $_{4}$-NC & 29.7 & 78.5 & 23.3 \\
L $_{5}$-NC & 26.3 & 87.1 & 22.9 \\
\hline
\end{tabular}

Note: Space velocity of acetylene was $105 \mathrm{~h}^{-1}$ and reaction temperature was $80^{\circ} \mathrm{C}$. The data is the average of three independent runs. 

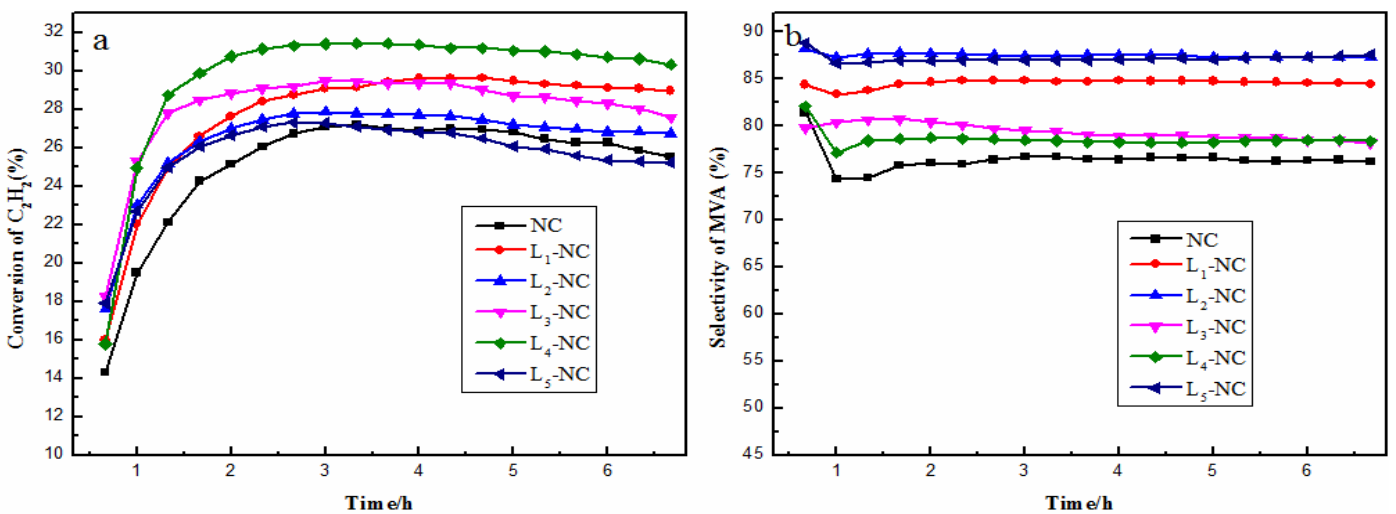

Figure 1. (a) Conversion of $\mathrm{C}_{2} \mathrm{H}_{2}$ and (b) selectivity to monovinylacetylene (MVA) in acetylene dimerization over NC and L-NC. (Reaction conditions: Space velocity of acetylene $105 \mathrm{~h}^{-1}$, reaction temperature $80^{\circ} \mathrm{C}, 3 \%$ of $\mathbf{L}_{1}-\mathbf{L}_{5}$ ).
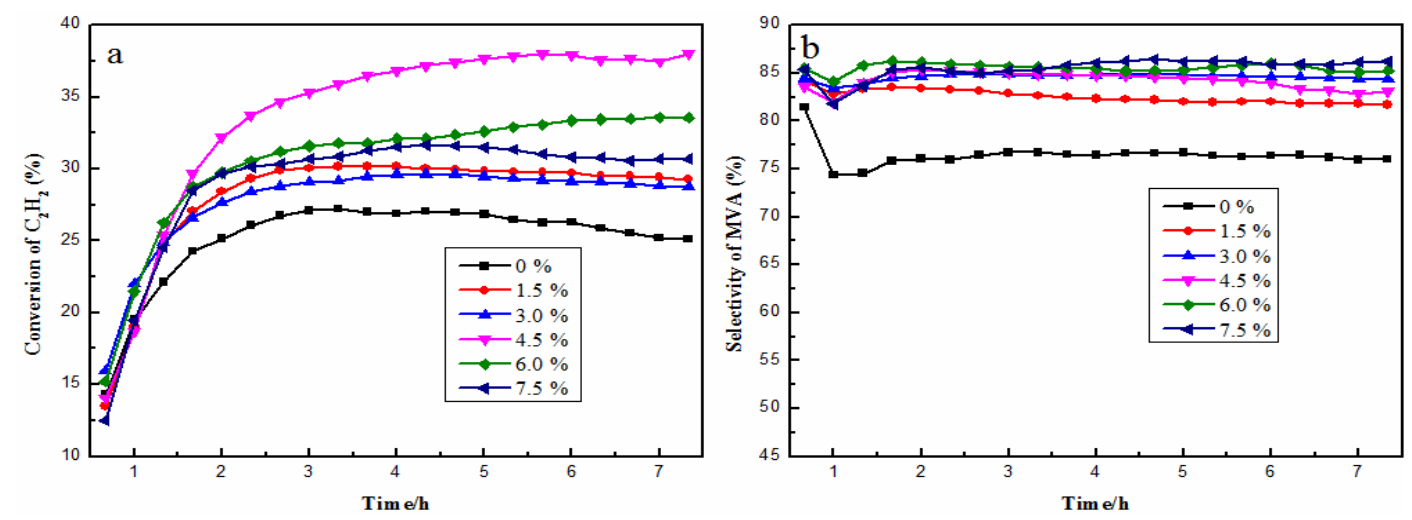

Figure 2. (a) Conversion of $\mathrm{C}_{2} \mathrm{H}_{2}$ and (b) selectivity to MVA in acetylene dimerization over $0-7.5 \%$ of $\mathbf{L}_{\mathbf{1}}$. (Reaction conditions: Space velocity of acetylene $105 \mathrm{~h}^{-1}$, reaction temperature $80^{\circ} \mathrm{C}$ ).

Table 2. Effect of the amount of $\mathbf{L}_{\mathbf{1}}$ for acetylene dimerization.

\begin{tabular}{cccc}
\hline $\mathbf{L}_{\mathbf{1}}(\mathbf{\%})$ & Acetylene Conversion (\%) & MVA Selectivity (\%) & Yield (\%) \\
\hline 0 & 26.4 & 76.4 & 20.1 \\
1.5 & 29.7 & 82.3 & 24.4 \\
3.0 & 29.2 & 84.7 & 24.7 \\
4.5 & 38.0 & 84.2 & 32.0 \\
6.0 & 32.5 & 85.5 & 27.8 \\
7.5 & 31.0 & 86.0 & 26.7 \\
\hline
\end{tabular}

Note: Space velocity of acetylene was $105 \mathrm{~h}^{-1}$ and reaction temperature was $80{ }^{\circ} \mathrm{C}$. The data is average of independent three runs.

\subsection{Stability Tests}

Long-term stability experiments were conducted to compare the catalytic stabilities and performances of NC, $\mathbf{L}_{\mathbf{1}}-\mathrm{NC}$, and $\mathrm{HCl}-\mathrm{NC}$ (Figure 3 and Table 3). $\mathbf{L}_{\mathbf{1}}-\mathrm{NC}$ exhibited an excellent catalytic performance and stability, and the acetylene conversion and MVA selectivity remained stable with no obvious decline observed within $24 \mathrm{~h}$. In contrast, NC and $\mathrm{HCl}-\mathrm{NC}$ exhibited distinctly lower catalytic performances and stabilities. 

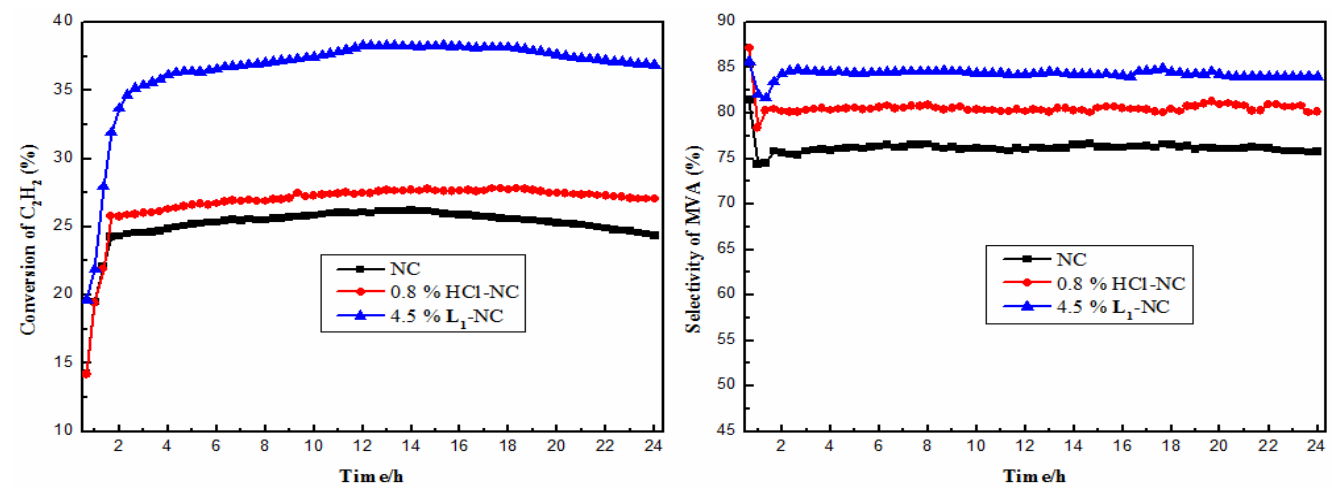

Figure 3. Catalytic performance of NC, $4.5 \% \mathrm{~L}_{1}-\mathrm{NC}$ and $0.8 \% \mathrm{HCl}-\mathrm{NC}$. (Reaction conditions: Space velocity of acetylene $105 \mathrm{~h}^{-1}$, reaction temperature $80^{\circ} \mathrm{C}$ ).

Table 3. Lifetime testing for three catalysts of NC, $4.5 \% \mathbf{L}_{\mathbf{1}}-\mathrm{NC}$ and $0.8 \% \mathrm{HCl}-\mathrm{NC}$.

\begin{tabular}{cccc}
\hline Catalysts & Acetylene Conversion (\%) & MVA Selectivity (\%) & Yield (\%) \\
\hline NC & 25.5 & 76.1 & 19.4 \\
HCl-NC & 27.2 & 80.5 & 21.9 \\
L $_{\mathbf{1}}-\mathrm{NC}$ & 37.5 & 84.4 & 31.7
\end{tabular}

Note: Space velocity of acetylene was $105 \mathrm{~h}^{-1}$ and reaction temperature was $80{ }^{\circ} \mathrm{C}$. The data is average of independent three runs.

\subsection{Structures of Crystals $A$ and $B$}

Considering the high efficiency of $\mathbf{L}_{1}$, we investigated the relationship between the structure of $\mathrm{NC} / \mathbf{L}_{1}-\mathrm{NC}$ and the catalytic activity. Then, we separated crystals A and B from solutions of NC and $\mathbf{L}_{1}$-NC via a freezing crystallization method, and we identified the composition of the crystals using FT-IR, TG, TPD-MS, XRD, XRF, and XPS analysis.

The FT-IR spectrum of crystal A is shown in Figure 4a. The peaks at $3169 \mathrm{~cm}^{-1}$ and $1393 \mathrm{~cm}^{-1}$ are characteristic peaks of $\mathrm{O}-\mathrm{H}$, and peaks representing $\mathrm{N}-\mathrm{H}$ appeared at $3445 \mathrm{~cm}^{-1}$ and $1643 \mathrm{~cm}^{-1}$ [18]. In the catalyst solution, $\mathrm{NH}_{4}^{+}$was hydrolyzed to produce $\mathrm{NH}_{3}\left(\mathrm{NH}_{4}^{+}+2 \mathrm{H}_{2} \mathrm{O}=\mathrm{NH}_{3} \cdot \mathrm{H}_{2} \mathrm{O}+\mathrm{H}_{3}^{+} \mathrm{O}\right)$; thus, we concluded that the crystal A contains $\mathrm{H}_{2} \mathrm{O}$ and $\mathrm{NH}_{3}$. As shown in Figure $4 \mathrm{~b}$, compared with $\mathbf{L}_{1}$, the N-H stretching absorption peak blue-shifted by approximately $70 \mathrm{~cm}^{-1}$, which indicated that $\mathrm{N}-\mathrm{H}$ was likely coordinated with $\mathrm{Cu}(\mathrm{I})$ in the copper complex. The peaks at $3161 \mathrm{~cm}^{-1}, 1400 \mathrm{~cm}^{-1}$, and $904 \mathrm{~cm}^{-1}$ were identified as the characteristic peaks of $\mathrm{O}-\mathrm{H}$ in the carboxyl group. The peak at $1718 \mathrm{~cm}^{-1}$ is due to the $\mathrm{C}=\mathrm{O}$ stretching vibration. The band located at $1064 \mathrm{~cm}^{-1}$ can be assigned to the $\mathrm{C}-\mathrm{N}$ stretching vibration. Therefore, crystal $\mathrm{B}$ may contain $\mathrm{H}_{2} \mathrm{O}, \mathrm{NH}_{3}$, and $\mathbf{L}_{1}$. These results were also confirmed by the TPD-MS spectrum (Figure 5) because a peak for the $m / z=17$ curve in the temperature range of $200{ }^{\circ} \mathrm{C}-350^{\circ} \mathrm{C}$ was obtained, which suggested that the weight loss corresponded to $\mathrm{NH}_{3}$.

To further determine the composition of the catalyst, we performed thermal analysis (TG) on crystals A and B (Figure 6). There were three weight losses for crystal A during the heating process. The first weight loss began at $100{ }^{\circ} \mathrm{C}$, which was mainly due to the loss of crystal water [10]. Obviously, the second weight loss was due to the loss of $\mathrm{NH}_{3}$ [18]. We calcined crystal A and crystal $\mathrm{B}$ in a tube furnace with nitrogen for $1 \mathrm{~h}$ at $450{ }^{\circ} \mathrm{C}$; XRD studies of the residues showed that they contained $\mathrm{CuCl}$ and $\mathrm{CuCl}_{2}$ (Figure 7). According to the TGA study for crystal A, three parts of the lost mass percentages were $0.28 \%, 30.04 \%$, and $69.68 \%$. However, there was one additional part of the weight loss between $375{ }^{\circ} \mathrm{C}$ and $405^{\circ} \mathrm{C}$ for crystal B, and for crystal B, the four parts of the lost mass percentages were $1.42 \%, 30.40 \%, 3.58 \%$, and $64.6 \%$. XRF examination of crystals $\mathrm{A}$ and $\mathrm{B}$ showed that their $\mathrm{Cu} / \mathrm{Cl}$ atomic ratios were both 2:3. Consequently, we can conclude that the compositions of crystal $\mathrm{A}$ and $\mathrm{B}$ are $\mathrm{Cu}_{2} \mathrm{Cl}_{3} \cdot 6 \mathrm{NH}_{3} \cdot 1 / 20 \mathrm{H}_{2} \mathrm{O}$ and $\mathrm{Cu}_{2} \mathrm{Cl}_{3} \cdot 1 / 10 \mathrm{C}_{4} \mathrm{H}_{7} \mathrm{NO}_{4} \cdot 13 / 2 \mathrm{NH}_{3} \cdot 3 / 10 \mathrm{H}_{2} \mathrm{O}$, respectively. 

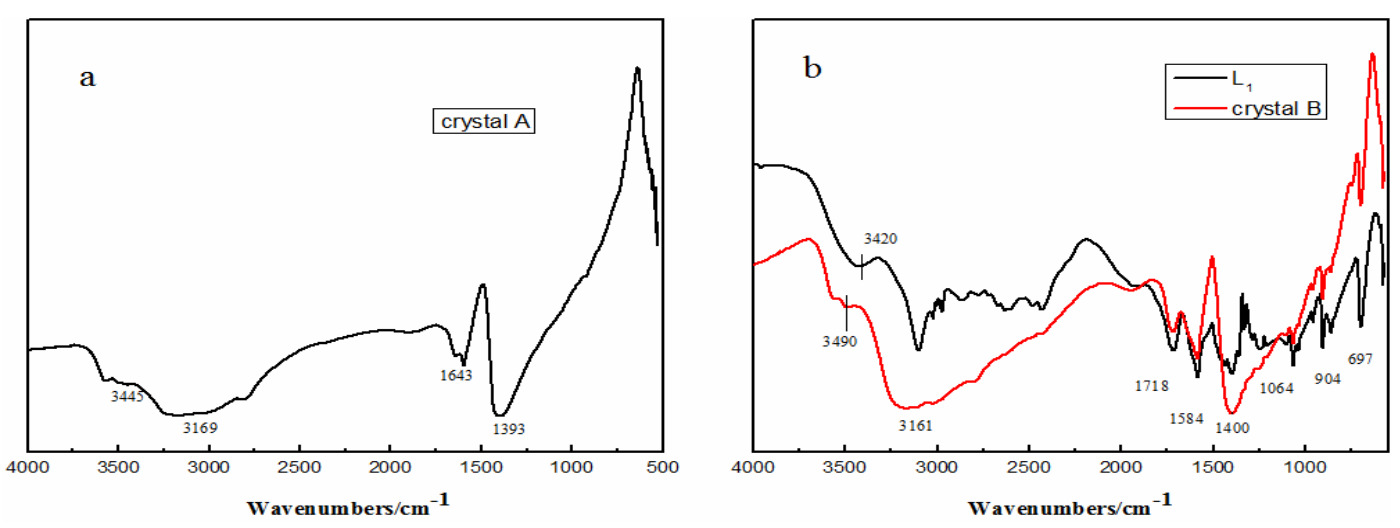

Figure 4. IR spectra of the crystal A (a), crystal B and $\mathbf{L}_{\mathbf{1}}(\mathbf{b})$.

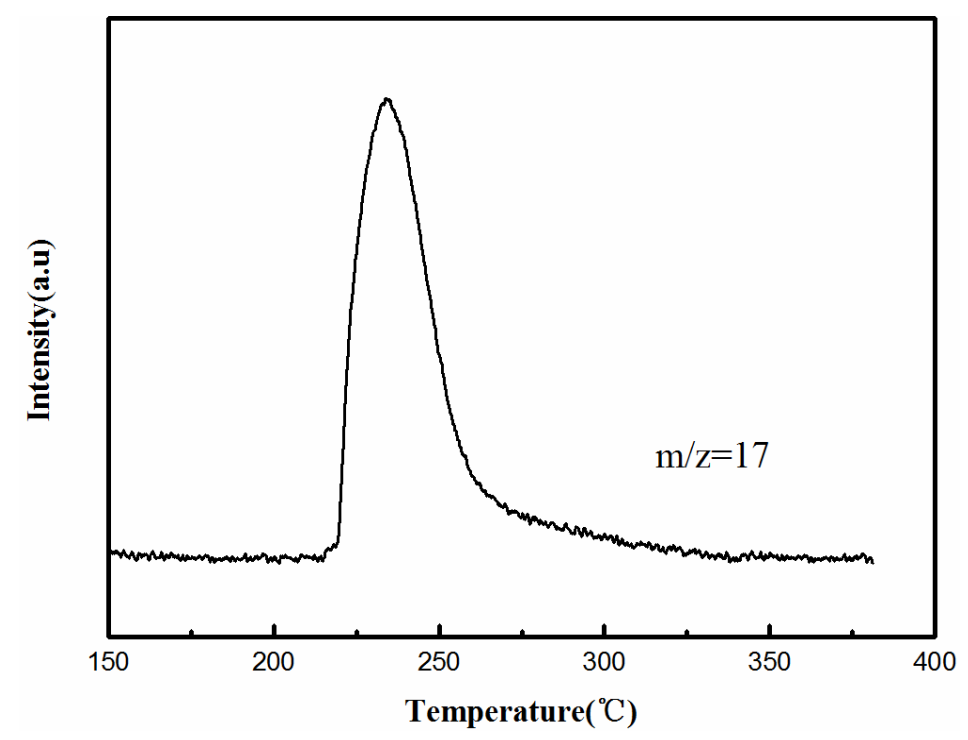

Figure 5. TPD-MS spectra of desorption of crystal A and B.
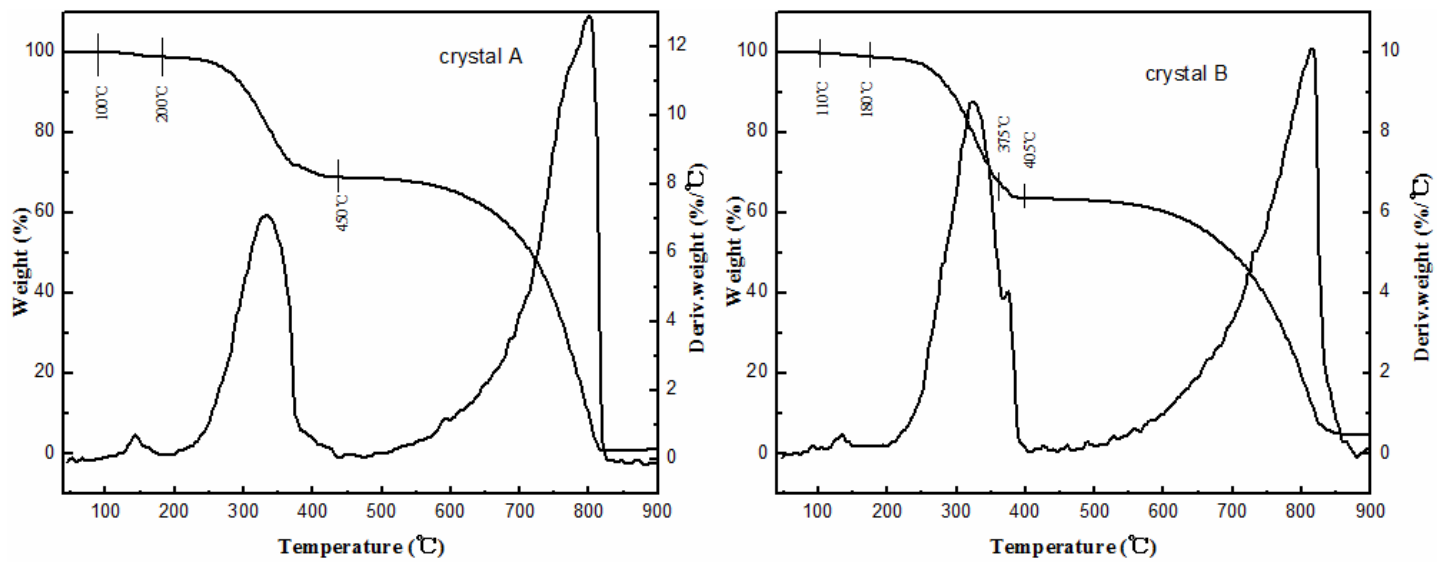

Figure 6. TG/DTG thermograms for the crystal A and crystal B. 

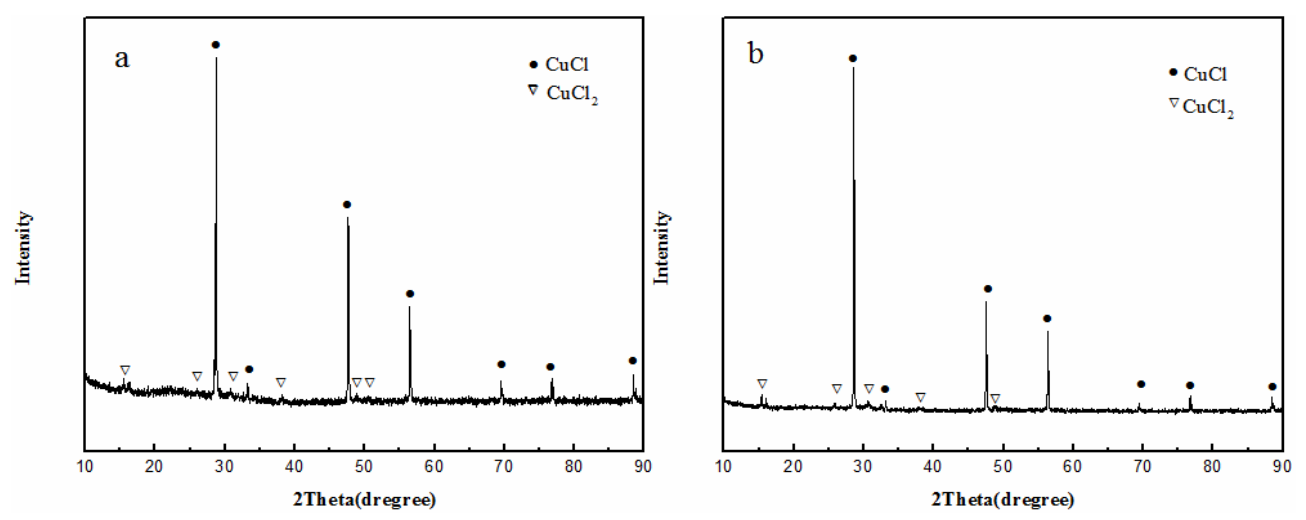

Figure 7. XRD pattern of heating product of the crystals A (a), B (b).

\subsection{Action of the Ligand}

As shown in Figure 8, the XPS results revealed that the binding energy of $\mathrm{Cu} 2 \mathrm{p}_{3 / 2}$ for crystal B exhibited a $0.26 \mathrm{eV}$ higher negative shift compared with crystal A. This negative shift is attributed to the interaction between $\mathbf{L}_{1}$ and copper ions, which increases the electron density of $\mathrm{Cu}^{+}$due to the transfer of electrons from $\mathrm{L}_{\mathbf{1}}$ to the $\mathrm{Cu}^{+}$center. This result was also supported by the TG analysis results of crystal B, whereas a higher desorption temperature for $\mathbf{L}_{\mathbf{1}}$ in crystal B was required.

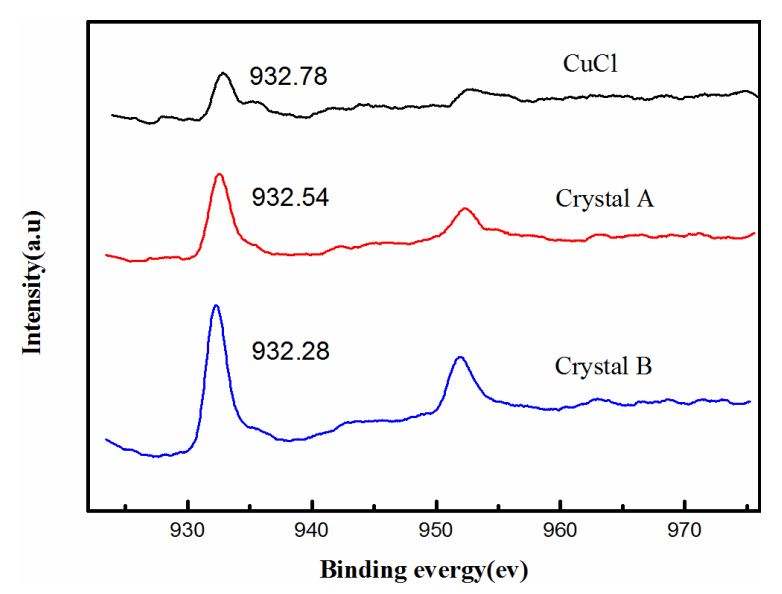

Figure 8. XPS spectra of Crystals A, B and $\mathrm{CuCl}$ for $\mathrm{Cu} 2 \mathrm{p}$.

As mentioned above, the higher electron density of $\mathrm{Cu}(\mathrm{I})$ lead to a higher catalytic performance in acetylene dimerization. Therefore, $\mathbf{L}_{\mathbf{1}}-\mathrm{NC}$ exhibited the best catalytic performance (higher acetylene conversion and MVA selectivity) and stability as described in Figures 1 and 3, which was due to the strongest electronic donating and coordination capability of $\mathbf{L}_{\mathbf{1}}$ with $\mathrm{Cu}(\mathrm{I})$ among the five tested ligands [11]. Recently, Han et al. reported that the addition of a certain amount of hydrochloric acid to the Nieuwland catalyst can inhibit the formation of the polymer and improve the catalyst lifetime and acetylene conversion [18]. Fukuzumi et al. also reported that the addition of $2.86 \mathrm{~mol} \%$ diethylenetriaminepentaacetic acid (DTPA) can increase the maximum yield of MVA and improve the product ratio of MVA to DVA, which may be due to the coordination of DTPA to the copper(I) active species affected the stability of the copper(I)-MVA and copper(I)-DVA complexes [1]. However, the present used additive $\mathbf{L}_{\mathbf{1}}$, which has a similar structure to DTPA but with more weak chelating ability and acidity, demonstrated higher catalytic performance. Therefore, both appropriate coordinate ability and acidity are important factors for an additive to enhance the catalytic activity and catalyst lifetime. At this point, $\mathbf{L}_{\mathbf{1}}$ is more suitable than DTPA for acetylene dimerization in large-scale application in industry. 


\subsection{Relationship between the Valence of Copper and Catalytic Activity}

$\mathrm{The} \mathrm{Cu}^{+}$ion is generally considered to be the main active component in the NC system. However, our previous studies found that $\mathrm{Cu}^{2+}$ also plays an important role in the acetylene dimerization reaction, and the deactivation of the anhydrous $\mathrm{NC}$ was caused by the transformation of $\mathrm{Cu}^{+}$to $\mathrm{Cu}^{2+}$ [9]. Hence, valence changes for copper species in fresh and used $\mathrm{NC}$ and $\mathbf{L}_{\mathbf{1}}-\mathrm{NC}$ were evaluated via high-resolution XPS, and the results are shown in Figure 9 and Table 4.
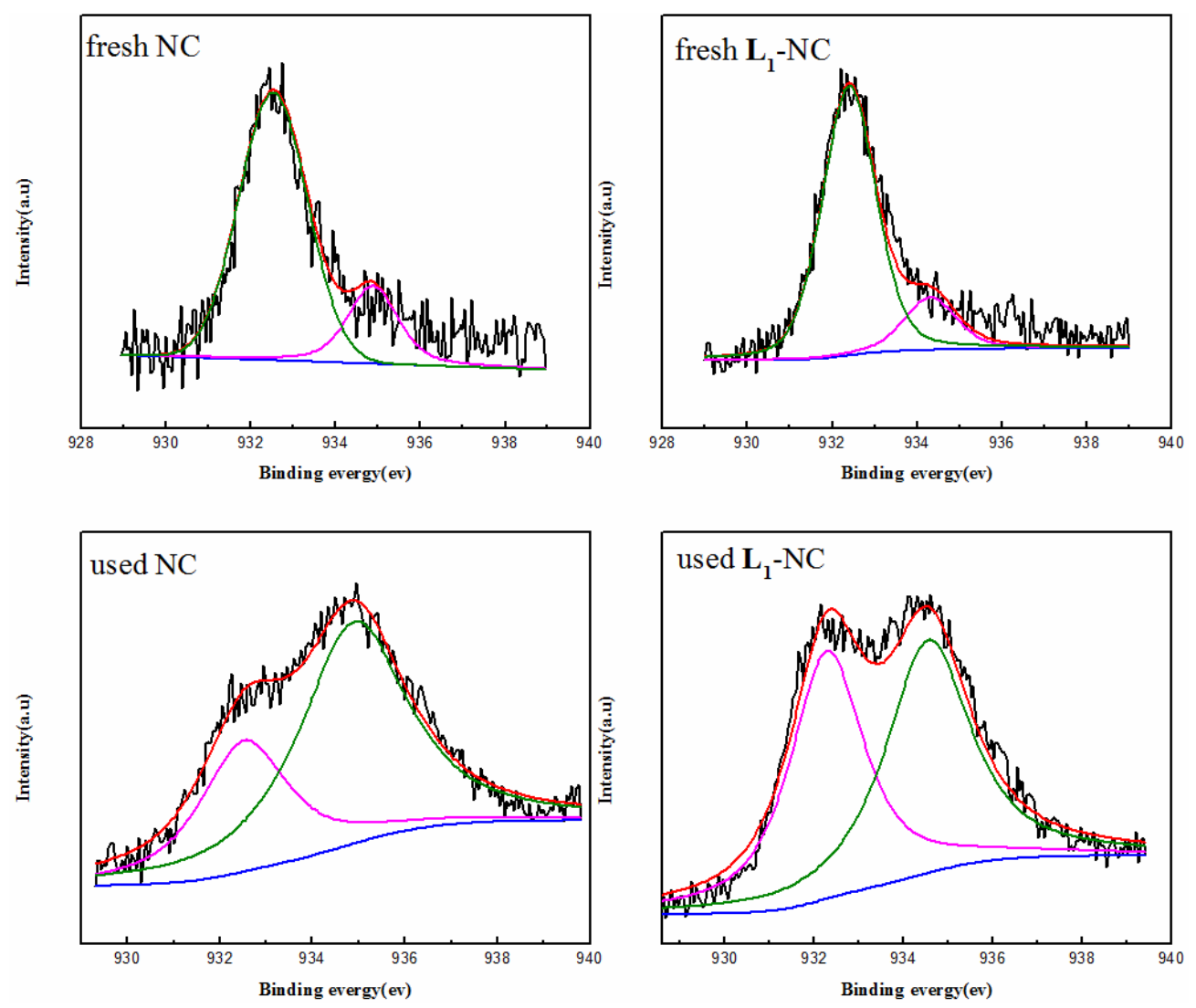

Figure 9. High-resolution XPS spectra of fresh NC, $\mathbf{L}_{\mathbf{1}}-\mathrm{NC}$ and used $\mathrm{NC}, \mathbf{L}_{\mathbf{1}}-\mathrm{NC}$.

Table 4. Relative content and binding energy of $\mathrm{Cu}^{+}$and $\mathrm{Cu}^{2+}$ in fresh catalyst.

\begin{tabular}{ccccc}
\hline \multirow{2}{*}{ Catalyst } & \multicolumn{4}{c}{ Area\%, Binding Energy (eV) } \\
\cline { 2 - 5 } & \multicolumn{3}{c}{$\mathbf{C u}^{+}$} & \multicolumn{2}{c}{$\mathbf{C u}^{2+}$} \\
\cline { 2 - 5 } & Fresh & Used & Fresh & Used \\
\hline NC & $79.09(932.53)$ & $32.85(932.51)$ & $20.91(934.87)$ & $67.15(934.88)$ \\
$\mathbf{L}_{\mathbf{1}}-\mathrm{NC}$ & $83.14(932.31)$ & $48.50(932.30)$ & $16.86(934.51)$ & $51.50(934.56)$ \\
\hline
\end{tabular}

In fresh $\mathrm{NC}$, peaks at 932.53 and $934.87 \mathrm{eV}$ represented $\mathrm{Cu}^{+}$and $\mathrm{Cu}^{2+}$, which had relative contents of $79.09 \%$ and $20.91 \%$, respectively, whereas the peak positions of $\mathrm{Cu}^{+}$and $\mathrm{Cu}^{2+}$ were at 932.31 and $934.51 \mathrm{eV}$, respectively, with relative contents of $83.14 \%$ and $16.86 \%$ for fresh $\mathbf{L}_{1}-\mathrm{NC}$. However, the contents of $\mathrm{Cu}^{+}$in the used NC and $\mathbf{L}_{1}-\mathrm{NC}$ were $32.85 \%$ and $48.50 \%$, respectively. The higher content of $\mathrm{Cu}^{+}$in used $\mathbf{L}_{1}-\mathrm{NC}$ in comparison with that in the NC may be because $\mathbf{L}_{1}$ inhibited the reduction of $\mathrm{Cu}^{2+}$ to $\mathrm{Cu}^{+}$. These results explain why $\mathbf{L}_{\mathbf{1}}-\mathrm{NC}$ possesses a higher initial catalytic activity and has a longer long-term lifetime than NC. 


\section{Experimental}

\subsection{Materials and Catalyst Preparation}

Reagent-grade $\mathrm{CuCl}(99 \%), \mathrm{NH}_{4} \mathrm{Cl}$ (purity $\left.\geq 99.5 \%\right)$, iminodiacetic acid $\left(\mathbf{L}_{\mathbf{1}}\right), 2$-(1H-pyrazol-1yl)acetic acid $\left(\mathbf{L}_{2}\right), 1 H$-tetrazole-1-acetic acid $\left(\mathbf{L}_{3}\right)$, diglycolic acid $\left(\mathbf{L}_{4}\right)$, and guanidineacetic acid $\left(\mathbf{L}_{5}\right)$ were purchased from Adamas (Shanghai, China).

The traditional Nieuwland catalyst was labeled as NC. The Nieuwland catalysts containing $\mathbf{L}_{\mathbf{1}}$, $\mathbf{L}_{2}, \mathbf{L}_{3}, \mathbf{L}_{4}$, and $\mathbf{L}_{5}$ were denoted as $\mathbf{L}_{\mathbf{1}}-\mathrm{NC}, \mathbf{L}_{2}-\mathrm{NC}, \mathbf{L}_{3}-\mathrm{NC}, \mathbf{L}_{4}-\mathrm{NC}$, and $\mathbf{L}_{5}-\mathrm{NC}$, respectively. The initial amounts of $\mathbf{L}_{1}-\mathbf{L}_{5}$ are $3.0 \mathrm{~mol} \%$ based on cuprous chloride $(0.60 \mathrm{~g}, 0.56 \mathrm{~g}, 0.57 \mathrm{~g}, 0.60 \mathrm{~g}$ and $0.53 \mathrm{~g}$, respectively). The structure of the five ligands was shown in Figure 10.<smiles>O=C(O)CNCC(=O)O</smiles>

$\mathbf{L}_{1}$ : iminodiacetic acid<smiles>O=C(O)Cn1cnnn1</smiles>

$\mathbf{L}_{3}: 1 H$-tetrazole-1-acetic acid<smiles>O=C(O)Cn1cccn1</smiles>

$\mathbf{L}_{2}:$ 2-(1H-pyrazol-1-yl)acetic acid<smiles>O=C(O)COCC(=O)O</smiles><smiles>N=C(N)NCC(=O)O</smiles>

$\mathbf{L}_{4}$ : diglycolic acid

$\mathbf{L}_{5}$ : guanidineacetic acid

Figure 10. The structure of the five ligands.

\subsection{The Structure of the Reactor}

The reaction was performed in a self-designed glass reactor with a length of $400 \mathrm{~mm}$, an outer diameter of $40 \mathrm{~mm}$, an inner diameter of $20 \mathrm{~mm}$. The reactor inner diameter contains the catalyst solution. A sand core baffle was used at the lower end of the reactor to increase the contact area between acetylene and the catalyst solution. The outer diameter was filled with circulating water to control the temperature of the reactor.

\subsection{Catalyst Preparation and the Dimerization Reaction of Acetylene}

The flow diagram of acetylene dimerization device is shown in Figure 11. Before the start of the reaction, the air in the pipe was removed by nitrogen during $30 \mathrm{~min}$ of continuous nitrogen flow. Then, $8 \mathrm{~g}$ of $\mathrm{NH}_{4} \mathrm{Cl}$ and $15 \mathrm{~mL}$ of deionized water were added to the bubbled bed reactor at $80^{\circ} \mathrm{C}$ under nitrogen atmosphere. After the mixture bubbled for approximately $10 \mathrm{~min}, 14.81 \mathrm{~g}$ of $\mathrm{CuCl}$ and a quantity of $\mathbf{L}_{1}-\mathbf{L}_{5}$ was added to the reactor under nitrogen atmosphere for at least $15 \mathrm{~min}$ until these solids got completely dissolved; then, the catalyst was obtained. The flow of $\mathrm{C}_{2} \mathrm{H}_{2}$ was regulated by a mass flowmeter. The gases in $\mathrm{C}_{2} \mathrm{H}_{2}$, such as $\mathrm{H}_{2} \mathrm{~S}, \mathrm{PH}_{3}$, and $\mathrm{O}_{2}$, were destroyed by $\mathrm{K}_{2} \mathrm{Cr}_{2} \mathrm{O}_{7}$ and $\mathrm{Na}_{2} \mathrm{~S}_{2} \mathrm{O}_{4}$ solutions. The acid gas and water were eliminated using a $\mathrm{NaOH}$ solution and a drying tube, respectively. Then, the purified $\mathrm{C}_{2} \mathrm{H}_{2}$ flowed into a preheated catalyst-containing glass reaction vessel. The gas mixture at the outlet of the reactor was analyzed via chromatography using a Shimadzu (Suzhou, China) GC-2014C equipped with a GDX-301 chromatography column and a flame ionization detector. 


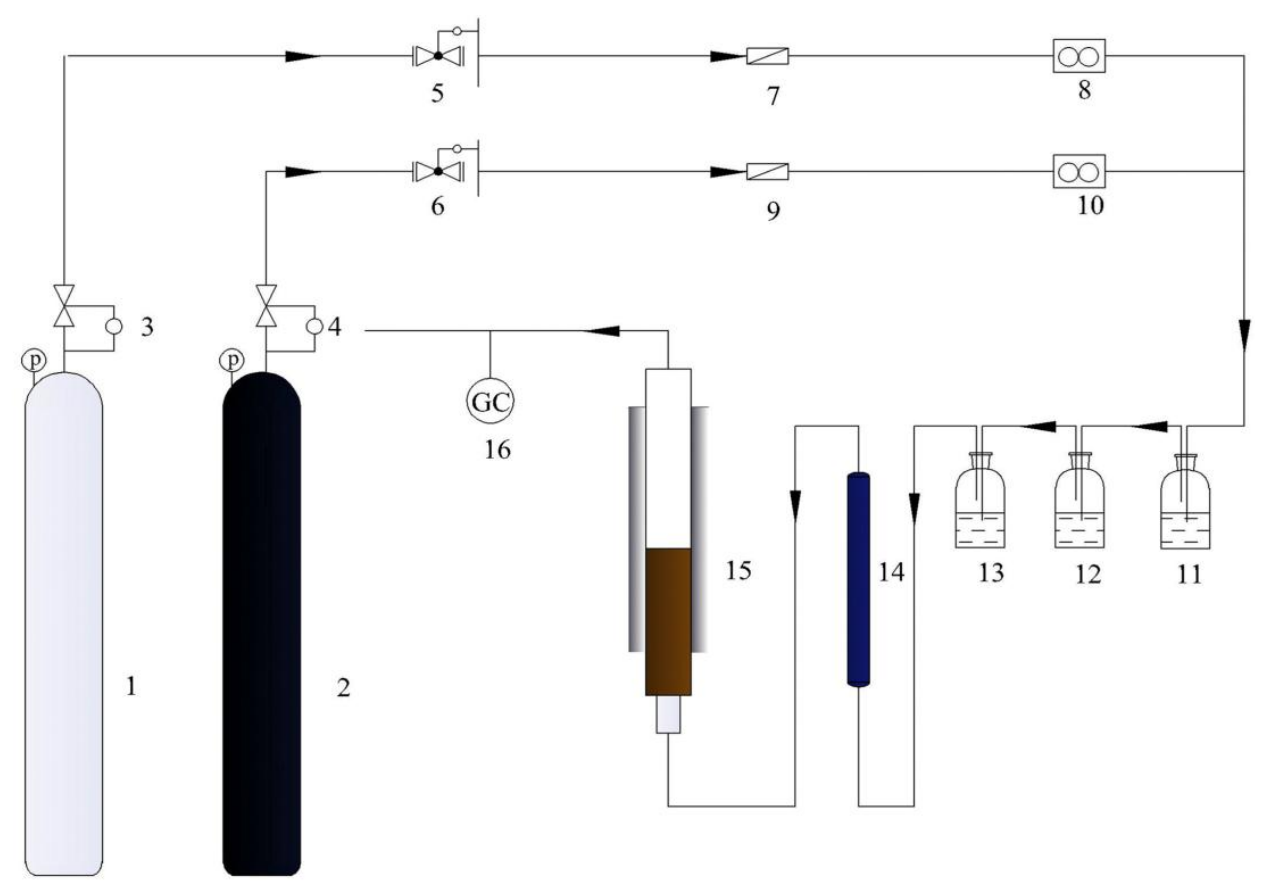

Figure 11. Schematic diagram of the $\mathrm{C}_{2} \mathrm{H}_{2}$ dimerization system: $1 \mathrm{C}_{2} \mathrm{H}_{2} ; 2 \mathrm{~N}_{2} ; 3,4$ partial pressure valve; 5, 6 check valve; 7, 9 gas filter; 8,10 mass flow controller; $11 \mathrm{~K}_{2} \mathrm{Cr}_{2} \mathrm{O}_{7}$ solution; $12 \mathrm{Na}_{2} \mathrm{~S}_{2} \mathrm{O}_{4}$ solution; $13 \mathrm{NaOH}$ solution; 14 drying tube; 15 reactor; 16 Gas Chromatograph (GC-2014C).

\subsection{Analytical Methods}

The conversion of $\mathrm{C}_{2} \mathrm{H}_{2}(X)$ and the selectivity to MVA $(S)$ as the criteria of catalytic performance were defined as following equations, respectively.

$$
\begin{gathered}
X=\left[\left(\lambda_{2}+2 \lambda_{3}+2 \lambda_{4}+3 \lambda_{5}\right) /\left(\lambda_{1}+\lambda_{2}+2 \lambda_{3}+2 \lambda_{4}+3 \lambda_{5}\right)\right] \times 100 \% \\
S=\left[2 \lambda_{3} /\left(\lambda_{2}+2 \lambda_{3}+2 \lambda_{4}+3 \lambda_{5}\right)\right] \times 100 \%
\end{gathered}
$$

where, $\lambda_{1}, \lambda_{2}, \lambda_{3}, \lambda_{4}$ and $\lambda_{5}$ are considered as the volume fraction of acetylene, acetaldehyde, MVA, 2-chloro-1,3-butadiene and 1,5-hexadien-3-yne (DVA) in the gas product.

\subsection{Separation of Crystals $A$ and $B$ from the NC and $L_{1}-N C$ Solutions}

Crystal A was obtained by gradually cooling the $\mathrm{NC}$ at $3{ }^{\circ} \mathrm{C}$. It was filtrated and was washed thrice with deionized water, and then, it was dried in a vacuum oven at $55^{\circ} \mathrm{C}$. The $\mathbf{L}_{1}-\mathrm{NC}$ was treated using the same method to obtain crystal B.

\subsection{Treatment of the Used Catalyst Solutions}

After the acetylene dimerization reaction occurred, the polymer in the catalyst solution containing $\mathrm{NC}$ or $\mathbf{L}_{1}-\mathrm{NC}$ was filtered, and the catalyst solution was dried in a vacuum oven at $55^{\circ} \mathrm{C}$.

\subsection{Catalyst Characterization}

FT-IR spectra of the samples in the range of 500 to $4000 \mathrm{~cm}^{-1}$ were obtained using a Bruker (Karlsruhe, Gemany) Vertex70.

TG-DTG of the samples was carried out using a NETZSCH (Bavaria, Germany) STA 449 F3 Jupiter under a nitrogen atmosphere. The temperature was increased from $50{ }^{\circ} \mathrm{C}$ to $900{ }^{\circ} \mathrm{C}$ at a rate of $10{ }^{\circ} \mathrm{C} \mathrm{min}-1$. 
X-ray diffraction (XRD) patterns were collected using a Bruker (Karlsruhe, Germany) D8 Advanced X-ray diffractometer with $\mathrm{Cu}-\mathrm{K} \alpha$ irradiation $(\lambda=1.5406 \AA)$ at $40 \mathrm{kV}$ and $40 \mathrm{~mA}$ at wide angles $\left(10^{\circ}-90^{\circ}\right.$ in $\left.2 \theta\right)$.

A Kratos AXIS Ultra DLD spectrometer (Manchester, UK) with a monochromatized, Al-K $\alpha$ X-ray source $(225 \mathrm{~W})$ was used to record the XPS data.

Elemental analysis of the crystals was carried out via X-ray fluorescence (XRF) using a Shimadzu (Tokyo, Japan) XRF-1800 system (Rh target) at $40 \mathrm{kV}$ and $1 \mathrm{~mA}$ with HS Easy software.

TPD-MS experiments were carried out using a Micromeritic (Atlanta, GA, USA) ASAP 2720 apparatus equipped with a TCD detector.

\section{Conclusions}

We demonstrated an iminodiacetic acid-assisted aqueous Nieuwland catalyst for the acetylene dimerization reaction that can achieve a $38.0 \%$ yield for acetylene conversion and an $85 \%$ yield for MVA selectivity with an increase in yield of $12 \%$ relative to the Nieuwland catalyst system. In this transformation, iminodiacetic acid not only provides proper acidity of the catalyst solution but also prevents $\mathrm{Cu}^{+}$oxidation to $\mathrm{Cu}^{2+}$, which are beneficial for the catalytic activity and stability. Further investigations on acetylene dimerization using this strategy are ongoing in our laboratory and will be reported in the future.

Acknowledgments: We acknowledge National Natural Science Foundation of China (No. 21463021 and 21776179) for their financial support.

Author Contributions: Jianwei Xie and Bin Dai received the project. Yanhe You and Juan Luo performed the experiments and analyzed the spectra data. Yanhe You, Jianwei Xie and Bin Dai wrote the paper.

Conflicts of Interest: The authors declare no conflict of interest.

\section{References}

1. Tachiyama, T.; Yoshida, M.; Aoyagia, T.; Fukuzumi, S. Mechanistic study on dimerization of acetylene with a Nieuwland catalyst. Appl. Organomet. Chem. 2008, 22, 205-210. [CrossRef]

2. Rattanasom, N.; Kueseng, P.; Deeprasertkul, C. Improvement of the mechanical and thermal properties of silica-filled polychloroprene vulcanizates prepared from latex system. Appl. Polym. Sci. 2012, 124, 2657-2668. [CrossRef]

3. Ismail, H.; Leong, H.C. Curing characteristics and mechanical properties of natural rubber/chloroprene rubber and epoxidized natural rubber/chloroprene rubber blends. Polym. Test. 2001, 20, 509-516. [CrossRef]

4. Arutyunyan, R.M.; Pogosyan, V.S.; Simonyan, E.H.; Atoyants, A.L.; Djigardjian, E.M. In situ monitoring of the ambient air around the chloroprene rubber industrial plant using the Tradescantia-stamen-hair mutation assay. Mutat. Res. 1999, 426, 117-120. [CrossRef]

5. Liu, J.G.; Han, M.H.; Zuo, Y.Z.; Wang, Z.W. Research progress of dimerization of acetylene to monovinylacetylene. Chem. Ind. Eng. Prog. 2011, 30, 942-947. [CrossRef]

6. Nishiwaki, K.; Kobayashi, M.; Takeuchi, T.; Matuoto, K.; Osakada, K. Nieuwland catalysts: Investigation of structure in the solid state and in solution and performance in the dimerization of acetylene. J. Mol. Catal. A Chem. 2001, 175, 73-81. [CrossRef]

7. Tokita, Y.; Okamoto, A.; Nishiwaki, K.; Kobayashi, M.; Nakamura, E. Kinetics of copper(I)-catalyzed dimerization and hydration of acetylene in water. Bull. Chem. Soc. Jpn. 2004, 77, 1395-1399. [CrossRef]

8. Tachiyama, T.; Yoshida, M.; Aoyagi, T.; Fukuzumi, S. Deuterium kinetic isotope effects and H/D exchange in dimerization of acetylene with a Nieuwland catalyst in aqueous media. J. Phys. Org. Chem. 2008, 21, 510-515. [CrossRef]

9. Liu, H.Y.; Xie, J.W.; Liu, P.; Dai, B. Effect of $\mathrm{Cu}^{+} / \mathrm{Cu}^{2+}$ Ratio on the Catalytic Behavior of Anhydrous Nieuwland Catalyst during Dimerization of Acetylene. Catalysts 2016, 6, 120. [CrossRef]

10. Liu, J.G.; Han, M.H.; Wang, Z.W. Studies on the catalytic performance of the Nieuwland catalyst and anhydrous catalyst in the dimerization of acetylene to monovinylacetylene. Adv. Mater. Res. 2012, 550-553, 312-316. [CrossRef] 
11. Liu, J.G.; Han, M.H.; Wang, Z.W. Effect of solvent on catalytic performance of anhydrous catalyst in acetylene dimerization to monovinylacetylene. J. Energy Chem. 2013, 22, 599-604. [CrossRef]

12. Liu, H.Y.; Xie, J.W.; Liu, P.; Liu, Z.Y.; Dai, B. Study on anhydrous catalyst in acetylene dimerization to monovinylacetylene. J. Shihezi Univ. 2015, 33, 622-627. [CrossRef]

13. Han, M.H.; Liu, J.G.; Zuo, Y.Z.; Wang, Z.W. Nieuwland Catalyst Preparation Method and Application. CN Patent 103285931 A, 27 February 2012.

14. Han, M.H.; Liu, J.G.; Zuo, Y.Z.; Wang, Z.W. Monovinylacetylene Product and Preparation Method of Monovinylacetylene. CN Patent 103288572 A, 11 September 2013.

15. Tao, C.Y.; Du, J.; Fan, X.; Liu, Z.H.; Xiao, C.C.; Ma, J.X.; Xue, H.T.; Shen, H.N.; Sun, D.G.; Liu, R.L. A Method of Preparing Hydrous Catalyst of Synthesizing Monovinylacetylene. CN Patent 101940953 A, 12 January 2011.

16. Tao, C.Y.; Du, J.; Fan, X.; Liu, Z.H.; Xiao, C.C.; Ma, J.X.; Xue, H.T.; Shen, H.N.; Sun, D.G.; Liu, R.L. An Improved Water System Nieuwland Catalyst and Its Application. CN Patent 101733150 A, 18 December 2009.

17. Tao, C.Y.; Du, J.; Fan, X.; Liu, Z.H.; Sun, D.G.; Shen, H.N.; Liu, R.L.; Zuo, Z.H.; Xiao, C.C.; Zhen, X.X. A Method of Preparing Catalyst of Synthesizing Monovinylacetylene and Application. CN Patent 101786022 A, 28 July 2010.

18. Liu, J.G.; Zuo, Y.Z.; Han, M.H.; Wang, Z.W.; Wang, D.Z. Stability improvement of the Nieuwland catalyst in the dimerization of acetylene to monovinylacetylene. J. Nat. Gas Chem. 2012, 21, 495-500. [CrossRef]

19. Liu, J.G.; Zuo, Y.Z.; Han, M.H.; Wang, Z.W. Improvement of anhydrous catalyst stability in acetylene dimerization by regulating acidity. J. Chem. Technol. Biotechnol. 2013, 88, 408-414. [CrossRef]

20. Liu, Z.H.; Yu, Y.L.; Tao, C.Y.; Du, J.; Liu, R.L.; Fan, X.; Peng, M.; Sun, D.G.; Zuo, Z.H.; Ma, J.X. A Method of Dimerization of Acetylene to Monovinylacetylene. CN Patent 102775266 A, 14 November 2012.

21. Han, M.H.; Liu, J.G.; Zuo, Y.Z.; Wang, Z.W. The Method and Application of Anhydrous Nieuwland Catalyst during Dimerization of Acetylene. CN Patent 103285925 A, 11 September 2013.

22. Liu, Z.H.; Yu, Y.L.; Tao, C.Y.; Fan, X. Acetylene dimerization catalyzed by $\mathrm{LaCl}_{3}$-modified Nieuwland catalyst. CIESC J. 2014, 65, 1260-1266. [CrossRef]

23. Liu, Z.H.; Yu, Y.L.; Tao, C.Y.; Du, J.; Liu, R.L.; Fan, X.; Peng, M.; Sun, D.G.; Zuo, Z.H.; Ma, J.X. A Method of Synthesizing Monovinylacetylene in Aqueous Solution. CN Patent 102731241 A, 17 October 2012.

24. Du, J.; Liu, Z.H.; Tao, C.Y. A Method of Synthesizing Monovinylacetylene. CN Patent 102964198 A, 13 March 2013.

25. Zhang, Y.K.; Jia, Z.K.; Zhen, B.; Han, M.H. Investigation of the acetylene dimerization catalyzed by Nieuwland catalyst. CIESC J. 2016, 67, 294-299. [CrossRef]

26. Lu, J.L.; Xie, J.W.; Liu, H.Y.; Liu, P.; Liu, Z.Y.; Dai, B. Strontium chloride modified Nieuwland catalyst in the dimerization of acetylene to monovinylacetylene. Asian J. Chem. 2014, 26, 8211-8214. [CrossRef]

27. Lu, J.L.; Liu, H.Y.; Xie, J.W.; Liu, P.; Liu, Z.Y.; Dai, B. Study on catalytic activity of zinc(II)-copper(I) collaborative bimetallic catalysis in acetylene dimerization reaction. J. Shihezi Univ. 2014, 32, $213-217$. [CrossRef]

28. Lu, J.L.; Liu, H.Y.; Xie, J.W.; Liu, P.; Dai, B.; Liu, Z.Y. Effect of polyethylene glycol/Nieuwland catalyst on acetylene dimerization reaction. Chem. Eng. 2015, 43, 60-64. [CrossRef]

(C) 2017 by the authors. Licensee MDPI, Basel, Switzerland. This article is an open access article distributed under the terms and conditions of the Creative Commons Attribution (CC BY) license (http://creativecommons.org/licenses/by/4.0/). 